\title{
EL FRACASO DE ESPAÑA EN LA PRIMERA OCUPACIÓN DE LOS TERRITORIOS DEL GOLFO DE GUINEA
}

\author{
Lic. D. ${ }^{a}$ Genoveva González Fanjul
}

Sevilla. España

\section{INTRODUCCIÓN. Las relaciones de Portugal y España en la época de Carlos III}

La larga historia de las relaciones diplomáticas de Portugal con Castilla y después con España, resulta a veces incomprensible, dificil de interpretar y llena de ambigüedades y suspicacias por condicionamientos más externos que internos y por motivaciones más coyunturales que estructurales, que se convierte en una constante, que aún hoy día se mantiene.

Si los Tratados de San Ildefonso de 1 de octubre de 1777 y del Pardo de 11 de marzo de 1778 (los últimos grandes tratados peninsulares), celebrados entre la España de Carlos III y el Portugal de Doña María 1, hay quienes puedan y quieran interpretarlo como un frenazo al expansionismo lusitano en la América meridional o como el inicio del continuado y total fracaso de la política española africana, más en concreto en el Golfo de Guinea, también presentan aspectos, no diría inéditos, pero sí de los que se ha dicho y escrito poco; me refiero al hecho de la interpretación de estos tratados como paradigma de las siempre problemáticas relaciones entre España y Portugal y el documento y prueba fehaciente en la que se contiene el primer intento serio y no improvisado en que la Monarquia española, se plantea la explotación y el Comercio de Negros, alli donde estaban sus fuentes, aunque circunstancias muy diversas malograran. Destacar estos dos aspectos, es lo que nos proponemos en el presente trabajo.

La muerte del Rey portugués Don José (1777), la crisis económica que atraviesa Portugal y la desaparición de la escena política del Marqués de Pombal, responsable de las transformaciones más profundas de la política, de la economía y de la sociedad portuguesa en los tiempos modernos, suponen un cambio importante y una coyuntura que van a aprovechar Carlos III y la nueva Reina de Portugal Doña María 1; convencidos españoles y portugueses de la necesidad de replantearse en profundidad sus relaciones y de llegar a un acuerdo, a Madrid había sido enviado como embajador don Francisco de Souza 
Coutinho y a Lisboa, el Marqués de Almodóvar, autorizados a negociar con Floridablanca y Ayres de Sa e Mello un tratado de paz, amistad, comercio y limites.'

\section{EL TRATADO DE SAN ILDEFONSO}

Así llegamos a primero de octubre de 1777 en que se firma el Tratado de San Ildefonso, ratificado por Carlos III en el Escorial el día 11 del mismo mes, entre las. Monarquias de Madrid y Lisboa. Este Tratado preliminar de otros posteriores, compuesto por veinticinco artículos y siete cláusulas secretas, fija los limites de las posesiones españolas en América del Sur; a España se le reconoce la posesión de las dos orillas de los ríos de la Plata y del Uruguay hasta la confluencia del río Piquiri con el Uruguay, devolviéndosele la Colonia del Sacramento, Isla de Sacramento y demás establecimientos discutidos en la orilla izquierda del Plata, mientras que España cede a Portugal la Isla de Santa Catalina y las provincias de Rio Grande y Santa Catarina.

Además de lo dicho anteriormente, se establece un tratado secreto por el que Portugal también cedía a España las Islas de Fernando Poo y Annobón en el Golfo de Guinea, con el acuerdo de que la cesión de dichas islas, no se haria pública mientras las autoridades españolas no la hubieran ocupado.

El 18 de octubre de 1777, o sea días después de firmado el Tratado, Floridablanca, sin duda impaciente por la evolución de los acontecimientos exteriores, en los que España se veía implicada, entra en contacto con el embajador de España en Lisboa, Marqués de Almodóvar para que recabe del Ministro portugués Ayres de Sa e Mello, la formalización de la entrega de las Islas del Golfo de Guinea. La actitud de Lisboa no satisface a Floridablanca.

"Califica V.E. omisión notable, dice a Floridablanca, no haber mandado las órdenes respectivas a la cesión de las islas de la costa de Africa. cuando entendia yo que esas óndenes de nada servirian sin convenir antes el modo de ejercitarlas, creyendo que seria lo mejor, que partieran de dos de nuestros puertos, dos embarcaciones llevando a los Comisarios, portugués y español, éste para tomar posesión y hacer en las Islas los establecimientos que le ordenase S.M.C. y aquel para hacer entrega de las islas, estando ya lista la embarcación que ha de salir de Lisboa, una vez sepa el sitio en que se ha de reunir con la española".

1 Despachos para a Legaçao de Portugal em Hespanha. Arquivo Nacional da Torre do Tombo. Lisboa (en adelante A.N.T.T.). Caja n ${ }^{\circ}$ (años 1668-1750) y n 2 (años 1758-1761).

El Rey portugués Don Juan V (1706-1750), casó a su hija Bárbara de Braganza con el después Rey de España, Fernando VI, y a su vez Felipe V de España, casó a su hija María Victoria con el Rey portugués Don José I (1750-1778); y según recoge la caixa n 2 del A.N.T.T. muerta Bárbara de Braganza se pensó casar otra vez a Fernando VI con las hermanas princesa de Portugal, gestionado este casamiento los Ministros Duque de Alba y Ricardo Wall, atrayéndose incluso con dinero a Muncio Farinelli; la muerte rápida de Fernando VI lo impidió.

La caja $\mathrm{n}^{\circ} 13$, recoge los matrimonios de Don Gabriel y Carlota Joaquina, hijas de Carlos III con Infantes portugueses.

2 Archivo General de Simancas. Legajo 7411. Folios 20-21-25 (en adelante A.G.S.) 
Nuevos escritos se cruzan entre Madrid y Lisboa; en 5 de noviembre, Ayres de Sa e Mello viene a decir a Floridablanca que no puede ser adivino de las previsiones que se hacian en San Ildefonso, referente a las Islas; Floridablanca, a lo que considera una insolencia, vivamente molesto, contesta el día 7 de noviembre: "Últimamente diré a V.E. que debiendo reinar entre las dos Cortes y entre nosotros mismos la cordial unión que desean establecer nuestros augustos Soberanos y habiendo yo contribuido a ese fin, más de lo que V.E. pueda pensar, de lo que está bien instruido el Rey Nuestro Señor no deja de serme perceptible un mal humor que suele verter al exterior de las cartas que me vienen de esa Corte. Soy incapaz, por mis principios, de variar de máxima ni de abusar de esta insensibilidad. V.E. me conoce y yo también le conozco. Seamos pues tan amigos como conviene al servicio de nuestros Amos y desterremos reconvenciones, frases y desconfianzas, por ligeras que sean puesto que pensamos de un mismo modo."'

Efectivamente, las Cortes y la diplomacia de Lisboa y Madrid, si no se ignoran, van por lo menos por caminos diferentes; Floridablanca y José Gálvez, habían tomado previsiones secretas (que no participan a Lisboa) para posesionarse de las Islas; "importaba enormemente que esta cesión no se conociera en Europa antes de estar establecido el ejército en dichas islas (pensaban) y sobre todo (les) interesaba la ocupación para manumitirse del monopolio que ingleses, franceses holandeses, italianos y pornugueses ejercian en el comercio de negros, con el que se suministraba la mano de obra para el fomento de nuestros territorios americanos; no importa ceder a Portugal, si preciso fuera, terrenos en Río Grande a cambio de Guinea y sobre todo si con esto se obtenía una plena neutralidad de Portugal en la guerra que ya se vislumbraba con Inglaterra", como así fue (1779-1783). ${ }^{4}$

3 A.G.S. E. Legajo 7411 , folios 17 y 28.

Manuel Cencillo de Pineda en su libro y que seguimos continuamente, se convierte en un apologista del Brigadier Argelejo y es bastante duro con Varela Ulloa; para Argelejo Varela Ulloa era de carácter dominante por la conciencia de su valer; efectivamente Varela Ulloa sobresalió por sus trabajos cientificos, geográficos e
hidrográficos.

En la bibliografia consultada han sido básicos los libros siguientes:

- CENCILLO DE PINEDA, Manuel: El Brigadier Conde de Argelejo y su expedición Militar a Fernando Póo en 1778. Instituto de Estudios africanos. C.S.I.C. Madrid 1948. "En este libro se recogen igualmente la documentación del Archivo General de Indias, de la Biblioteca Nacional de Buenos Aires y del Archivo
General de Simancas".

- UNZUETA y YUSTE, A.: "El tratado del Pardo: Aspectos económicos. Madrid, 1947". REGLÁ CAMPISTOL, J.: "El reformismo del siglo XVII" en Introducción a la Historia de España. Edit. Teide. Barcelona 1972. Pág. 438 a 485.

- AGUADO BLEYE, p. y ALCÁZAR MOlNA, C: Manual de Historia de España. Página 234.

- OLIVEIRA MARQUÉS, A.H.: Historia de Portugal. Palas Edit. Lisboa 1972. Vol. II.

4 Instrucción reservada de Don José Gảlvez al Brigadier Conde de Argelejo, fechada en San Lorenzo el Real el 20 de octubre de 1777. A.G.S. E. Legajo 74l1, folio 5. AGUADO BLEYE, P. y ALCAZAR MOLINA, C.: Mamual de Historia de España. Página 234. 


\section{LAS EXPEDICIONES PORTUGUESAS Y ESPAÑOLAS AL GOLFO DE GUINEA}

Madrid, en noviembre de 1777, nada más terminado el Tratado de San Ildefonso había expedido órdenes secretas para que las fragatas, Santa Catalina mandada por Don José Varela U loa saliera de Cádiz el dia 18 y Nasa de la Soledad saliera del Ferrol el día 5 de diciembre; mandada ésta por Don Ramón Topete, llevando ambas, sendos ejemplares del Tratado de San Ildefonso y varios pliegos secretos con instrucciones, destinados al Virrey de Buenos Aires, a donde llegaron el día 21 de febrero de 1778. Lisboa, por otra parte, también había cambiado sus planes (sin comunicarlos), nombrando un nuevo Comisario portugués para la cesión de dichas islas, el Capitán de Navío de la Armada de S.M.F. Don Fray Luiz Cayetano de Castro, quien salió de Lisboa el día 21 de febrero de 1778.

Naturalmente ni uno ni otro Comisario, por muy bien que les fuera la navegación, podrían estar en el Golfo de Guinea para el mes de marzo de ese año, fecha prevista para la firma del Tratado del Pardo. La expedición española, procedente de Montevideo y compuesta por una flotilla de dos fragatas y un bergantín, mandadas por el Comandante de Marina don José Varela Ulloa, siendo Jefe de las fuerzas de tierra que iban a bordo, el Brigadier, Conde de Argelejo, nombrado también Comisario español para hacerse cargo de las islas, llegará a la Isla del Príncipe el 29 de junio de 1778.

La expedición portuguesa, como habiamos dicho, salió de Lisboa el 21 de febrero de 1778 y después de un desastroso viaje, que separa a sus barcos (viaje que critica Varela Ulloa, y que lleva a la fragata $\mathrm{N}^{\mathrm{a}} \mathrm{S}^{\mathrm{a}}$ de Gracia, que lleva al Comisario portugués a Pernambuco el dia 11 de agosto), no llegará a la Isla del Príncipe hasta el día 4 de octubre llevando además a Don Juan Manuel de Azambuja, nuevo Gobernador General de las Islas ya Don Joaquín de Almeida como Capitán Mayor de Santo Tomé; la llegada celebrada con grandes manifestaciones de júbilo por los naturales no lo fue menos por los españoles que llevaban tres meses esperándola.

Esta larga espera, el clima y las enfermedades, quebrantaron el ánimo de los españoles, produciéndose enfrentamientos con los naturales de las islas y entre ellos mismos; a todo esto hay que añadir la intransigencia del Gobernador de la Isla del Príncipe, en entregar dichas islas a España, a pesar de los documentos que se le mostraban, quien decia, que según las cartas de su Reina y Señora, tenía que ser precisamente al Sr. Ramires de Esquivel, de no recibir aviso en contrario; actitud esta que merecerá del Brigadier Argelejo, la amenaza y aviso, de que toda responsabilidad que pudiera derivarse de las acciones que adoptara, serfan de la plena responsabilidad de dicho Gobernador, por su conducta "entretenida dolosa".

No era esto lo más lamentable sino el enfrentamiento que se va a producir entre Argelejo y Varela Ulloa; para Argelejo, no era necesario esperar providencias de la Corte de Madrid en aquel momento y asunto, pues ya tenian los poderes para pasar a las Islas, hacer un establecimiento con su artillería y fuerzas de tierra, con lo que las fragatas quedarian a resguardo y en mejor estado de defensa y se podría ocultar las flaquezas, caso de que enfermasen más españoles, lo que se temía en el caso de que ocurriera la guerra; Varela Ulloa, 
también tenia clarisima su postura: habia recibido órdenes, de que fuera a tomar posesión de las Islas con asistencia del Comisario portugués y que no habiendo llegado éste, sería contravenir las instrucciones del Rey, dar cualquier paso en este asunto sin esa expresa circunstancia.

Después de repetidas Juntas y cambio de pareceres, no encuentran los Jefes de la expedición española otra solución que transbordarlos efectos que llevaban al bergantín Santiago y que partiera para España; sale el día 27 de septiembre de 1778 con noticias de lo que ocurría y a recibir instrucciones de Madrid, llegando a Cádiz el 1 de enero del 1779.

\section{EL TRATADO DEL PARDO}

En la creencia que el asunto del Golfo de Guinea estaba resuelto, se había firmado en Madrid el 11 de marzo de 1778, el Tratado del Pardo.

Este nuevo Tratado, que consta de diez y nueve artículos y que agota todas las expresiones de amistad y buenos deseos entre España y Portugal, no hace sino confirmar y revalidar, dando forma definitiva al Tratado de San Ildefonso, siempre considerado provisional y preliminar de otros tres, uno de alianza, otro de comercio y otro de límites; los dos primeros se refundieron en uno solo, que ajustó Floridablanca y se denominó Tratado de Amistad, Comercio, Neutralidad y Garantía recíproca y es del que hablamos y que se firma en el Pardo el día 11 de marzo; su inutilidad y fracaso queda demostrada al año siguiente en la Segunda Guerra que mantiene Carlos III con Inglaterra (1779-1783), a la que Portugal nuevamente se une.

El segundo de los Tratados, el de Límites, con sus operaciones demarcadoras nunca terminó y fue interrumpido en 180 1, con la llamada - Guerra de las Naranjas-, en que las tropas españolas, una vez más, invaden Portugal, capitaneadas por el Ministro Godoy, ahora aliado de la Francia Revolucionaria.

La ocupación y no devolución de Olivenza (Olivença, el Gibraltar. portugués), echó por tierra todo el edifico levantado en el Pardo en 1778.

En este artículo XIII queda meridianamente claro, además de la cesión de las Islas de Fernando Poo y Annobón, la intención manifiesta de la Corte de Madrid de ejercitar el Comercio de Negros: "Deseando S.S. MM. Católica y Fidelisima, promoverlas ventajas del comercio de sus respectivos súbditos, los cuales pueden verificarse en el que reciprocamente hicieren de compra y venta de negros, sin ligarse a contratas o asientos perjudiciales como los que en otro tiempo se hicieron con las Compañias Portuguesa, Francesa e Inglesa, los cuales fue preciso cortar y anular, se han convenido los dos altos Príncipes contrayentes en que, para lograr aquellos y otros fines..."

5 "Copia do Tratado que aprobó o Rey Católico qué está escrito nas duas linguas". Caja n 8. A.N.T.T. y Archivo General de Simancas. E. Legajo 7411 bis. Folio 6. Ver pág. 9. 


\section{EL FRACASO PORTUGUÉS Y ESPAÑOL EN LA CESIÓN Y TOMA DE POSESIÓN DE LAS ISLAS DEL GOLFO DE GUINEA}

El resumen escueto y resultado de esta primera expedición española para tomar posesión de las Islas, es el siguiente: el día 4 de octubre ha llegado el Comisario portugués don Frey Cayetano de Castro a Santo Tomé; días después salen las dos expediciones para Fernando Poo, la española que lleva como Comisario al Conde de Argelejo y además Jefe de las fuerzas de abordo y a Varela Ulloa como Comandante de marina de la expedición; el Comisario portugués va en la fragata Ni S' de Gracia; el día 21 de octubre echan ancla en una ensenada de Fernando Poo y bajan a tierra, tomando posesión, "sui generis", el Conde de Argelejo de aquella Isla y da el nombre de San Carlos al lugar donde han desembarcado, en obsequio al Rey de España; se dirigen después a Annobón y en el trayecto (14 de noviembre) muere el Conde de Argelejo, a quien le sustituye el teniente Coronel don Joaquín Primo de Rivera; después de varios intentos (28 a 30 de noviembre), de toma de posesión de Annobón, se fracasa; las dos expediciones, española y portuguesa, vuelven a Santo Tomé el dia 3 de diciembre, sin haber realizado sus objetivos.

Una vez en Santo Tomé, se acuerda que Primo de Rivera quede en aquella isla en espera de refuerzos e instrucciones de España en la fragata Santa Catalina, donde informa de todo lo ocurrido; un año después, el 20 de noviembre de 1779, llegan los refuerzos de España y Portugal; no hay acuerdo entre españoles y portugueses en esta segunda expedición; Primo de Rivera intenta una segunda toma de posesión, ahora sólo de Fernando Poo, a donde llega el día 7 de diciembre de 1779 llegando a la Bahía que llamó Concepción y funda ya un verdadero establecimiento, permaneciendo durante algún tiempo pero las privaciones, sufrimientos, bajas, enfermedades y sobre todo el amotinamiento de la tropa terminan con lo hecho; Primo de Rivera llegará preso por los amotinados de Fernando Poo a la Isla de Santo Tomé el dia 16 de noviembre de 1780, donde fue puesto en libertad por los portugueses; viendo fracasados todos sus intentos el 28 de febrero de 1783 se dirige a Montevideo de donde había salido cinco años antes, con 22 hombres de 150 que salieron. ${ }^{6}$

Habrá todavia un tercer pensamiento, el establecimiento de una base colonial y mercantil en dichas islas, El Ministro de Indias, Don José Gálvez, fundador y primer presidente de la Real Compañia de Filipinas, trató de establecer una colonia mercantil en dichas islas, destacando la utilidad que podría reportar a dicha Compañía, el tener una escala propia en sus viajes a Asia; la muerte de Gálvez, el gran impulsor y defensor del establecimiento de

6 Entre los llegados en este último intento de ocupación y que acompañan a Primo de Rivera en su segunda expedición destaca el comerciante don Miguel Lucas, quien elevaria a Don José Gálvez en 18 de septiembre de 1779, diferentes propuestas sobre el comercio de esclavos negros; a ellas contesta el 15 de octubre de 1780, el mismo Gálvez, lo siguiente: con motivo de la guerra y por esperar que se halla formado el establecimiento, no ha tenido el Rey por conveniente que se proceda a hacer el acopio de los efectos que contiene su factura de comercio para la compra y trata de negros pero se ejecutará luego que cese la Guerra. (A.G.S. E. Legajo 7411 , folio 98). 
España en el Golfo de Guinea en 1786, hace que se abandone el proyecto; nuevo fracaso de establecerse en el Golfo de Guinea y podriamos decir que por tercera vez.

A partir de ahora estos territorios van a ser olvidados oficialmente con la preocupación de las guerras con Inglaterra, después con Francia, la independencia de Hispano América; la dejación y vacío de la autoridad y soberanía española en aquellos territorios será una triste realidad hasta mediados del siglo XIX. El 12 de octubre de 1968 , se pone fin a la presencia de España en el Golfo de Guinea, que si desafortunada fue en sus comienzos, no tuvo mejor fin.

\section{DOCUMENTO N*1}

\section{RESUMEN DEL INFORME CONFIDENCIAL QUE DON JOSÉ VARELA Y ULLOA, COMANDANTE DE LAS EMBARCACIONES DESTINADAS A LAS ISLAS DE ANNOBON Y FERNANDO PÓO, ENVÍO AL MINISTRO DE MARINA EXCMO. SEÑOR MARQUÉS, GONZÁLEZ DE CASTEJON}

Muy Señor mío: Por el paquebote Santiago, que salió del puerto de la Isla del Príncipe, el 28 de septiembre del año próximo pasado (1778), informé a V.E. de todo lo acaecido a nuestra Comisión hasta aquella fecha; fáltame ahora informar de lo que ocurrió después, en que me vi obligado a salir del Golfo de Guinea y dejar en la Isla de Santo Tomé, la tropa, artillería y pertrechos consignados en la expedición.

El 4 de octubre, llegó la Fragata $N^{a} S^{a}$ de Gracia al mando de Don Frey Luis Cayetano de Castro, Capitán de Navío de la Armada de S.M.F. quien envió inmediatamente una carta al Brigadier Conde de Argelejo del Ministro de Indias, en la que decía que a pesar de haber sido nombrado por S.M.F. quien envió inmediatamente una carta al Brigadier Conde de Argelejo del Ministro de Indias, en la que decía que a pesar de haber sido nombrado por S.M.F. la Reina de Portugal como Comisario para la entrega de las Islas de Fernando Poo y Annobón el Capitán de Mar y Guerra Don Bernardo la entrega Ramires de Esquivel, cedidas a S.M.C. en el último Tratado de paz, había dispuesto que lo hiciera ahora Don Frey Luis Cayetano de Castro, autorizándole con nuevas órdenes dirigidas al Gobernador y Cámara de la Isla del Príncipe.

El día 5 fuimos a cumplimentar al Comandante Portugués, Sr. Castro, quien le cuenta toda la odisea para llegar al Golfo de Guinea; Varela critica la falta de pericia y la ruta tomada por el Sr. Castro; a continuación se presentaron al nuevo Gobernador Sr. Azambuja, diciéndoles cuáles eran sus planes.

El día 7, fuimos Argelejo y yo a bordo de la fragata portuguesa y el Sr. Castro nos expuso cuál era su misión: en primer lugar ir desde el Príncipe a Annobón y dejar allí un destacamento de soldados, después convocaría a los habitantes para manifestarles que S.M.F. había cedido aquella Isla al Rey de España, a quien por tanto debían prestar vasallaje y obediencia enarbolándose la bandera española; a continuacion irían a la Iglesia a dar gracias al Señor de todo lo actuado pero si los indígenas intimidados por las armas escapaban al bosque, correspondería al Comisario español volverles a juntar, reducir y civilizar a aquella gente. En segundo lugar se facultaba a Luis Cayetano de Castro, que entregase Fernando 
Póo, bien en la ciudad del Príncipe o en donde creyera conveniente, sin más formalidad que la de pasar a manos del Comisario español un certificado en el que se especificase, que desde esos momentos dicha Isla pertenecía al Rey Católico.

Yo, dice Varela, dije que no aceptaba eso pues tenía obligación de reconocer las costas, producciones, carácter de los habitantes, surgideros... de todo lo cual tenía que informar el Comisario portugués quedó contrariado y trató de convencerme que ir a Fernando Póo era peligroso porque sus habitantes eran indómitos, no reconocían vasallaje alguno y sobre todo peligraba nuestra salud por estar dicha isla en los más profundo del Golfo de Guinea; pero viendo que no desistiamos de nuestro propósito, aceptó a acompañarnos.

El dia 10 por la mañana, vino el Sr. Castro a mi bordo, manifestándome que de su parte suponía una condescendencia política y amistosa puesto que eso no estaba previsto en las instrucciones y me dio como explicación que los habitantes del Príncipe, decían que los negros de Fernando Póo, no reconocían el vasallaje de S.M.F. y que la mayor parte de ellos desconocían que existiese tal príncipe sobre la Tierra. "Tal era la idea, que nos daban estos fidalgos, dice Varela, de los derechos y acciones de S.M.F. en la Isla de Fernando Póo".

El día 13, después de estar todo preparado, comuniqué al Sr. Castro que estaba dispuesto a ir a Fernando Póo y el día 14 a las diez de la mañana salimos del puerto del Príncipe; al amanecer del día 15 avistamos la Isla, no habiendo acuerdo en el lugar de desembarco y asi estuvimos rodeando la isla hasta el dia 21 , en que se echó el ancla en el puerto de Fernando Póo; pusimos el nombre de San Carlos en obsequio del Soberano, pero no sin advertirnos que aquella navegación, era más nuestra que suya, a lo que Varela apostilla: "Raro modo de precaverse y extraña resolución en quien venía comisionado para entregarnos Fernando Póo".

Ahora Varela Ulloa hace una larga disertación sobre Fernando Póo y la compara con Annobón, y concluye: "Fernando Póo, es más a propósito que Annobón para escala de comercio, lo primero porque tiene una ensenada bastante segura, lo segundo porque está cerca del Calabar, Río del Rey, Río de Camarones, Río Campo, Río San Benito y aún del Río Gabón, por lo que se pueden aprovechar estas circunstancias para la compra de esclavos, cera, marfil, y palos de tinte...".

Nada más entramos en el puerto de San Carlos, el Brigadier Conde de Argelejo y el ingeniero don Francisco de paula Esteban reconocieron la ensenada detenidamente y acordaron situar el establecimiento en la punta NE donde hay un riachuelo, buena playa y abrigo para lanchas $\mathrm{y}$ botes.

El día 24 por la mañana, bajamos los dos comisarios a tierra con un destacamento de tropa portuguesa y varios oficiales de Marina y del Ejército y llegado a un punto el $\mathrm{Sr}$. Castro, mandó a su escribano que leyera en voz alta el pliego de la Reina Fidelísima, en el que autorizaba al Comisario del Rey Católico llegar al Golfo de Guinea a fin de hacerle entrega de las Islas de Fernando Póo y Annobón a la Corona de España, según el último Tratado de Paz; terminada la lectura por el escribano, el Comisario portugués, dirigiéndose al Brigadier Conde de Argelejo le dijo: "que en virtud de los poderes que le había conferido Su Señora la Reyna, le entregaba la Isla de Fernando Póo, con todos los derechos, acciones y dominios que tenía en ella la Corona de Portugal, para que en igua- 
les términos la poseyera el Rey de España, a quien debían reconocer los habitantes como Rey y Señor".

A continuación, dice Varela, el Brigadier Conde de Argelejo proclamó a S.M.C. por Soberano de Fernando Póo, enarbolando en aquella Isla la bandera española, saludada con siete voces de, Viva el Rey, pero aunque se le habia dicho en las instrucciones que se hiciera una triple descarga de 21 cañonazos, pareció conveniente omitirlos, al Brigadier Conde de Argelejo, por no atemorizar a los habitantes, que por otra parte sin motivo alguno, habian abandonado el puerto desde el día que entramos en él.

Subido a bordo, el Brigadier Conde de Argelejo, comunicó a Varela de oficio, que la Isla de Fernando Poo quedaba ya por el Rey Nuestro Señor y que en esta seguridad podíamos hacer ya derrota a Annobón, a la vez que le declaraba las razones por las que se veía precisado a abandonar el proyecto de establecerse en el puerto de San Carlos; a continuación, Varela enumera hasta seis motivos que le da el Brigadier Argelejo el motivo de más peso que encuentro es el último de los enumerados que dice: "que el Comisario portugués, había dicho a Argelejo, que se comprometía a entregar Annobón con la obediencia del pueblo, edificios para cuarteles, hospital, almacenes de pólvora, por lo que, dice Argelejo, pensaba ir a dicha isla y permanecer alli, hasta recibir las órdenes del Rey".

A Varela Ulloa no le había gustado que el Brigadier Argelejo no consultara el asunto con él y si que lo hiciera con el Comisario portugués y los dos tenientes coroneles del Ejercito. Primo de Rivera y Francisco de Paula Esteban, (cosa que no la tiene en cuenta), pues como Comisario y Gobernador de aquellas islas, Argelejo tenía facultad de resolver por sí; pero con lo que no estaba de acuerdo y lo hace constar, era, "el modo como proclamó al Rey Nuestro Señor, Soberano de Fernando Poo, pues tanto Argelejo como yo, sabíamos que en aquella isla habían seis o siete mil personas, que de tiempo en tiempo, bajaban a la playa a pescar y a hacer algún tráfico con los ingleses que llegan de la costa fronteriza; así que hacer ver al Brigadier Conde de Argelejo, que no debía admitir la entrega de la referida isla, ni establecerse en ella, ínterin el Sr. Castro no obligara a los habitantes a reconocer la dominación española; esto no gusta a Argelejo, quien dice Varela, por un entusiasmo o capricho militar, enarboló la bandera del Rey en la ensenada de San Carlos, tomando posesión de árboles y montes, sin haber preguntado ni una sola vez, por los pretendido vasallos de S.M.F.

Sigue Varela: salimos de Fernando Poo y en la tarde del dia 24, logramos embarcar a un negrito de la isla, dándole por señas toda clase de seguridad; no pudimos sacar ninguna noticia de Fernando Poo, pues su lengua era desconocida a los negros del Príncipe y a los esclavos de la costa que llevábamos a bordo; se le enseñó después varias banderas y sólo conocía a la francesa e inglesa, manifestando alegria al ver esta última, de todas las demás, incluso de la portuguesa hizo un desprecio notable y añade Varela: "Tales la idea que tienen de S.M.F. los habitantes de Fernando Poo"; después de regalarle algunas cosas soltaron al negrito que se perdió rápido en el bosque.

El día 3 de noviembre, dejaban Fernando Poo, llegan al Principe, donde repostan y cuidan los enfermos, cuyo número era de setenta; el día 10 por la mañana ponen derrota para Annobón con tiempo claro y viento fresco; El Brigadier Conde Argelejo, que desde el día 24 de octubre, que se sintió enfermo en Fernando Poo de fiebres catarrales y una diarrea per- 
tinaz, muere nada más salir el día 14 de noviembre arrojándose al día siguiente su cadáver al mar y el 16 se participa al Teniente Coronel Don Joaquín Primo de Rivera que iba en la Fragata Soledad que se convertía en Jefe principal de la expedición.

Tras malos tiempos y tormentas con destrozos de los barcos, el día 26 se llega a Annobón, echando anclas a media milla de la población de Pareá, que es la principal de la Isla; el día 27, los dos Comisarios, se ponen de acuerdo en la forma de la entrega de la Isla; contra la opinión de Varela se había establecido que los isleños no supieran, cuál era el objeto de nuestro viaje, lo que merece la siguiente observación: "Esta proposición me pareció poco digna de un sujeto que venía autorizado para transmitirnos, los derechos, acciones, y posesiones de S.M.F. a la Isla de Annobón".

El dia 28 por la mañana, bajaron los Comisarios a tierra con una escolta de 24 soldados portugueses y oficiales de Marina y del Ejército de ambas naciones a los que recibió el Capitán Mayor de la Isla y los condujo a la iglesia, donde se celebró una misa; terminada esta el Sr. Castro dijo al Capitán Mayor (hombre de gran consideración en la isla y nativo de ella) que informados el Rey y la Reina, nuestros Señores y Soberanos, que los ingleses querian tomar la isla y no pudiéndoles defender por tener otras tierras, habían decidido cederlas con todos sus derechos al Rey de España; el Capitán Mayor y el Sacristán, después de un rato de silencio, dijeron que no habian oído hablar nunca de tal Príncipe. Don Luis de Castro trató de convencerlos, diciendo que el Rey de España era hermano del Rey de Portugal y que siendo sus vasallos tendrian que comer y vestir y que el Capitán Mayor seguiría en su empleo.

Tanto el Sacristán como el Capitán Mayor, insistian en que no conocían al Rey de España y además que la isla era estéril y pequeña y que si la entregaban a los blancos, ellos acabarían esclavizados, cosa que no permitirian aunque les cortaran la cabeza; en fin no había modo de convencerlos y decide el Si. Castro que se celebre otra misa y no habiendo surtido efecto, pues tanto el Sacristán como el Capitán Mayor, repetían que si quería matarlos alli estaban, trató de amenazarlos haciendo cargar las armas a los soldados; el pueblo se alborota organizando una procesión con crucifijos, cruces de madera, calaveras, huesos de difuntos, haciendo ademanes y arrodillándose.

Ante esto, el Sr. Castro se dirige al Teniente Coronel Primo de Rivera y le dice, que ya tenía evacuada su misión, que era ponerlos en tierra y "que todo lo demás corría de cuenta de los españoles". A esto, contesta Primo de Rivera que tenía orden de su Soberano de tomar posesión de la Isla sin la menor hostilidad y por lo tanto no se quedaran alli, a menos que el pueblo jurara fidelidad al Rey Católico, según lo dispuesto por S.M.F.

Don Luis de Castro, no encontraba medios para poner fin al problema; comunica al Sacristán y al Capitán Mayor que se retiraban a bordo y después de unas horas enviaría por la respuesta, dejando a uno de sus capellanes para convencer a los isleños; Castro poco después sube a la Fragata española donde informa de la repugnancia que manifiestan los isleños en someterse al Rey de España; en esta conversación, Varela hace ver al Sr. Castro, el fraude con que habia procedido la Corte de Lisboa en el Tratado de Paz, aparentando unos derechos, acciones y posesiones sobre Fernando Poo y Annobón que sólo habia existido en la mente del Sr. Gomes Ferreira por los falsos informes que había enviado al Ministro de Portugal. 
El día 29 a las ocho de la mañana, otra vez bajan todos a tierra, con 25 hombres de marina y 15 de la tropa del ejército y llegan a la puerta de iglesia donde los isleños, con gritos y amenazas y con una macabra procesión con calaveras, féretros, huesos de difuntos, candilejas... muestran su disconformidad; el Sr. Castro reacciona mandando a los portugueses montar sus fusiles y bayonetas, el pánico cunde y hasta él mismo se ve obligado a defenderse a golpe de espada; entran en la iglesia, donde hay un gran griterío y alboroto, pide al Sacristán y al Capitán Mayor que hablen el pueblo, cosa que no consiguen; entonces uno de los capellanes portugueses alzando la voz, amenazó con la excomunión a los que no obedecieran las ordenes de S.M.F. lo que de momento aplacó un poco los ánimos, ocasión que aprovecha el Comisario portugués para pedir que reconocieran como Soberano al Rey de España a lo que respondieron con impresionante griterío que no; ante esto otra vez el capellán portugués indignado, amenaza a todos, hombres y mujeres de la isla con estas palabras: "Deito ao inferno homens e mulheres e a Ilha tuda" (sic). Las cosas se pusieron tan mal, que impotentes para mantener el orden, de nuevo sacan sus armas y el Capitán Mayor y el Sacristán escaparon al bosque; detenido el Sacristán por un soldado, el mismo Don Luis de Castro le dio varios golpes con gran escándalo de los isleños que decían: Sacristans, Sacristans, Ministro de Deus; el sacristán puesto de rodillas decía al Comisario: "Señor, yo nada valgo, matadme, que moriré por Nuestro Señor Jesucristo, dominador de cielos y tierra".

Ante esto Don Frey Luis Cayetano, preguntó a Don Joaquín Primo de Rivera y a mi, qué partido pensábamos tomar en aquellas circunstancias. Le dijimos que estábamos muy satisfechos de cuantas diligencias había practicado para el desempeño de su comisión pero que no era posible admitir la entrega de las Islas. Don Luis de Castro arrastró y condujo a bordo a algunos de los negros más revoltosos que con toda franqueza le dijeron: que el Rey Fidelísimo no tenía dominio en aquella isla y que los habitantes le trataban de protector pero nunca de Soberano.

Un día más permanecieron en la isla con nuevos enfrentamientos y enteramente frustrados nuestros deseos y no quedando la más mínima esperanza de establecemos en Annobón, Don Joaquín Primo de Rivera y yo acordamos que en la fragata de mi mando yo marchase a España para informar al Rey de todo y que la fragata Soledad quedara en la Isla de Santo Tomé esperando las instrucciones de S.M. El Comisario Sr. Castro que al final había dado pruebas de armonía y buena correspondencia lo comprendió todo; dijo que él se iba a la Bahía de Todos los Santos a carenar su fragata y a esperar las órdenes de S.M.F. "sobre lo que debía executar con los habitantes de Annobón, cuya falta de obediencia era digna de un severo castigo".

Varela Ulloa, hace una especie de reflexión final: "V.E. me prevenía en las instrucciones que los portugueses nos conducirian al Gobernador y a mí a los parajes de la costa que expresan los artículos reservados; como este asunto no se habia tratado aún con el Comisario portugués, le pasé un oficio preguntándole qué órdenes tenia de su Corte sobre el particular, a lo que me respondió con un certificado en los siguientes términos: "Don Frey Luis Cayetano de Castro, Profeso en la Religión de San Juan Capitán de Navio al servicio de S.M.F. Certifico, que sali de Lisboa con orden de hace viaje al Golfo de Guinea para entregar las Islas de Ano bón y Fernando del Pó al Comisario del Rey Católico y de regresar a 
aquel puerto, luego que esto se verificase $\mathrm{Al}$ ancla en la ensenada de Ano bom. 30 de noviembre de 1777 ".

El 1 de diciembre deseándonos Primo de Rivera y yo un buen viaje, mareamos en derrota a nuestros respectivos destinos; el día 19 reparada la embarcación pertrechado de lo necesario, salimos de Santo Tomé; asi navegamos todo el mes de enero, el dia 14 de febrero avistamos el Cabo de San Vicente y poniendo derrota para Cádiz entramos en dicho puerto, hoy a las cinco de la tarde. A bordo de la Santa Catalina, al ancla en la Bahía de Cádiz a 12 de marzo de 1779. Excmo. Sr. B.l.m. de V.E. su más atento rendido súbdito. (Firmado) José Varela y Ulloa. Excmo. Sr. Marqués, González de Castejón".

\section{DOCUMENTO 2 (16 MARZO DE 1779)}

"Excmo. Señor; Mui Señor mío y amigo, comunico a V.E. confidencialmente la adjunta carta de don Joseph Varela Ulloa, Comandante de las embarcaciones destinadas a las Yslas de Annobón y Fernando del Po. Por su contexto comprehenderá V.E. lo ocurrido en el acto de toma de posesión de ellas, cuya ocupación por las armas del Rey no se ha verificado, señaladamente en Annobón por la resistencia de los naturales.

La expedición se había visto precisada a regresar a Santo Tomé adonde quedaba; y ya ve V.E. que en fuerza de lo acaecido se halla el Rey en derecho de exigir con arreglo a la buena fé se le ponga en pacifica posesión de las Islas de Annobon y Fernando del Pó, o se le dé por la Reina Fidelisima un equivalente de ellas, tanto más que no faltan personas que claman contra el hecho de ceder más Yslas, cuya propiedad no tenía asegurada la Corte de Lisboa.

En estas circunstancias, me ocurre como muy correspondiente a la amistad que media entre el Rey y la Reyna Fidelísima el expediente de que providencie esta "Soberana, se permita a los vasallos españoles establecerse por ahora interinamente en la Ysla de Sto. Tomé o en la del Príncipe, lo cual sobre ser tan propio de la buena fé de la Corte de Lisboa y necesario para proceder desde alli a la reducción de las Yslas, conducirá para que empiecen las dos Naciones a obrar unidas, ayudándose mutuamente a contrarrestar la oposición y extorsiones que los portugueses experimentan de parte de algunas Potencias Extrangeras en su Navegación y. Comercio de Negros, cuyo pensamiento sabe V.E. ha nacido del Ministerio Lusitano.

Espero que V.E. hará el debido uso de esta confianza amistosa despachando un Correo a su Corte con noticia de todo, y sirviéndose comunicarme la determinación de la Reyna Fidelísima, que deberá considerarse como una nueva prueba de su sinceridad y amistad verdadera, y de sus deseos de estrechar los vínculos de recíproca buena harmonía que median entre ambas Coronas, apartando todo motivo de desconfianza.

Pido a V.E. me devuelva la carta de Varela que le comunico y acompaño los adjuntos pliegos, reiterando a V.E. mi afecto y obsequio, deseoso de que Dios guarde a V.E. muchos años El Pardo a 16 de marzo de 1779.

Excmo. Señor. Besa la mano de V.E. su m. afect. serv. y amigo. (Firmado, El Conde de Floridablanca).

Excmo. Señor Don Francisco Ynocencio de Souza Coutinho." 


\section{DOCUMENTO 3 (17 MARZO DE 1779)}

"Excmo. Señor: Muy Señor mío y amigo: Recibí con sumo disgusto las noticias que V.E. tiene la bondad de comunicarme en su carta confidencial referente al mal fin de la toma de posesión de las Yslas de Ano bom y Fernando del Pó; lo cual en realidad no influye sobre la buena fé de la cesión ni sobre su efecto; porque es notorio a toda Europa y se encuentra incluso escrito por autores extranjeros, como ya tuve el honor de manifestar a V.E. que la propiedad de estas Islas, era incontestablemente de la Reina, mi Ama, al tiempo en que las cedió a Su Majestad Católica y porque la brutalidad de los Negros, no es ni será ya más capaz, de admitir persuasiones que les hagan mudar de costumbres; el miedo sólo les sujeta y para este miedo no son necesarios grandes ejemplos de considerables estragos y del mismo modo que los miserables de Ano bom negaron ahora el reconocimiento del dominio de Su Majestad Fidelísima, lo niegan todos los otros en que hay establecimientos de europeos; con todo, el respeto que estos les infunden les sujeta sin grandes esfuerzos.

En cuando a la dificultad del primer establecimiento, muchas veces dije a V.E. y al Señor Don José de Gálvez que eran grandes en las costas de Africa y que sólo un espíritu creador las vencía, siendo superior a los estragos que continuamente hace el clima; y asi no debe V.E. extrañarse de estos primeros embarazos y dificultades porque son comunísimos y en semejantes primeros establecimientos en cualquier región y muchos mayores en aquella.

Esto es todo lo que le puedo decir con seguridad absoluta; despacho el correo, dando cuenta a la Reina, mi Ama, y tendre el honor de comunicar a V.E. su Real Resolución; y porque no es posible concluir hoy la copia de la carta que V.E. me remite, devolveré el original pasado mañana, rogando a V.E. me disculpe ante la Real Presencia de Su Majestad Católica por la falta de mi Corte el día de mañana, estando muy preocupado por este despacho.

Queda siempre a las órdenes de V.E. con el mayor afecto y obsequio, deseando que Dios guarde a V.E muchos años. Madrid a 17 de marzo de 1779.

Excmo. Señor. Besa las manos de V.E. su más querido servidor y amigo. (Firmado) Don Francisco Ynocencio de Souza Coutinho.

Excmo. Señor Conde de Floridablanca."

\section{DOCUMENTO 4 (19 MARZO DE 1779)}

"Ilmo. y Excmo. Señor: Ayer me escribió el Conde de Floridablanca, la carta original que remito a V.E. y con la misma va una copia de los despachos de Luiz de Castro para el Señor Martinho de Mello incluidos en este; juzgué útil al servicio de Su Majestad responder al dicho Ministro de la forma que remito a V.E. la minuta, para tranquilizar los espíritus que ciertamente se alteraron mucho con estas nuevas porque no saben de qué se trata; $y$ crea V.E. que el pobre Ministro tendrá bastante que sufrir, pues es imposible pensar en un pueblo más insolente y charlatán que este, y si con la primeras noticias levantaron tan crueles mentiras, cuántas levantarán Y Publicarán ahora; y con todo debe apreciar V.E. que este Ministro dotado de la mejor buena intención que puede, escribe con la moderación que se ve y no usa de oficio, todo en obsequio de la buena unión de las dos Coronas que hacen la base fundamental de todo su sistema". ( ... ) "Todo esto tiene pase, pero como ve V.E. conviene verifi- 
car la buena fé de la cesión y que es necesario ayudar a los españoles a conseguirla; de balde diríamos que hemos dado lo que allí está y en el estado en que está..." (...) "El Duque de Losada, con quien comí ayer en casa del embajador de Alemania, que está en todos los secretos de los negocios de esta Corte y que es verdaderamente amigo nuestro, me hablo de los asuntos "más de actualidad" y me dijo que son el del (Tratado) Comercio y el de las Islas, preocupándose mucho de que pudiera haber dudas y me dijo estas palabras textuales: la obra que está hecha es la más bella y la más útil que jamás se ha hecho; los enemigos de Portugal y de España quieren por todos los medios abortarla para desunimos y coger ellos el fruto de la discordia de ambas Coronas; esta es la verdad.(... )

V.E. mandará lo que fuera servido. Dios guarde a V.E. muchos años. Madrid a 19 de marzo de 1779. (Firmado) Don Francisco Ynocencio de Souza Coutinho.

Excmo. Señor Ayres de Sa e Mello."”

\section{DOCUMENTO 5}

"No sé como Don José Varela, esperaba hallar en aquellas Islas, plazas y fortalezas de Portugal porque nunca se afirmó tal cosa a los Ministros españoles; por el contrario, se explicó toda la verdad de lo que eran dichas Islas cuando el Señor Floridablanca, lo único que quería era un refugio o agujero en la Costa de África. Examine V.E. mis despachos de 26 de julio y 30 de octubre de 1777 o de 11 de noviembre del mismo año o de 1 de julio de 1778 , en los que de modo claro y sincero se expuso el estado de las Islas y el modo de comerciar con las costas de África; lo cual será conveniente recordar ahora al Señor Floridablanca en confirmación de nuestra buena fé y para que no haga caso a las voces que se levantan maliciosamente o con ignorancia de los hechos.(Carta del Ministro portugués Ayres de Sa e Mello al entonces embajador de España en Lisboa, Conde de Fernán Núñez). ${ }^{g}$

7 Caja (caixa) n 10. "Ministerio dos Negocios Estrangeiros. Despachos para a legaçao de Portugal em España". Oficios del embajador en Madrid de Portugal Don Francisco Inocencio de Souza Coutinho. A.N.T.T.

8 A.G.S., E. Legajo 7411 , folio 11. 